\title{
A cross-cultural perspective of medical clowning: comparison of its effectiveness in reducing pain and anxiety among hospitalized Bedouin and Jewish Israeli children
}

\author{
This article was published in the following Dove Press journal: \\ Journal of Pain Research \\ 5 July 2017 \\ Number of times this article has been viewed
}

\author{
Zehavit Gilboa-Negari' \\ Sarah Abu-Kaf ${ }^{2}$ \\ Ephrat Huss' \\ Gavriel Hain ${ }^{3}$ \\ Asher Moser ${ }^{4}$ \\ 'Spitzer Department of Social \\ Work, Ben-Gurion University of the \\ Negev, Beer-Sheva, Israel; ${ }^{2}$ Conflict \\ Management and Resolution Program, \\ Ben-Gurion University of the Negev, \\ Beer-Sheva, Israel; ${ }^{3}$ Department \\ of Pediatrics, Soroka University \\ Medical Center, Beer-Sheva, Israel; \\ ${ }^{4}$ Department of Pediatric Oncology, \\ Soroka University Medical Center, \\ Beer-Sheva, Israel
}

\begin{abstract}
Purpose: Medical clowning has proven effective for reducing pain, anxiety, and stress, however, its differential effects on children from different cultures have not yet been researched. This study evaluated the effects of medical-clowning intervention on anxiety and pain among Jewish and Bedouin children, and anxiety among their parents, in southern Israel.
\end{abstract}

Patients and methods: The study was conducted in hospital pediatric departments and employed a pre-post design involving quantitative and qualitative methods. The study included 89 children whose ages ranged from 7.5 to 12 years (39 Jewish and 50 Bedouin) and 69 parents (19 Jewish and 50 Bedouin). Questionnaires assessing pain, anxiety, and demographics were used at the pre-intervention stage and pain, anxiety, and enjoyment of different aspects of the intervention were evaluated following the intervention. The intervention stage lasted for 8-10 minutes and included the use of word play, body language, and making faces, as well as the use of props brought by the clown. Semi-structured interviews were also conducted at the post-intervention stage.

Results: The intervention reduced pain and anxiety among both groups of children and reduced anxiety among both groups of parents. However, anxiety levels were reduced more significantly among Bedouin children. The nonverbal components of the clowns' humor were most central, but it was the verbal components that mediated the reduction in anxiety among the Bedouin children. Conclusion: This study underscored the effectiveness and importance of medical clowning in reducing pain and anxiety among children in different cultural contexts. Moreover, the issue of culturally appropriate humor was underscored and implications for intercultural clown training are discussed. Keywords: humor, cultural contexts, intervention, pre-post design, parents, pediatric departments, nonverbal component

\section{Introduction}

Humor is a universal phenomenon ${ }^{1}$ but the specific components of humor depend on society, culture, and social context. The boundaries of humor, which relate to the things at which one may and may not laugh and who can and cannot serve as the butt of a joke, are based on cultural norms. ${ }^{2}$ Apart from the issue of cultural borders, there is also an element of subjective interpretation. Humor is often complex linguistically and so it may be challenging for second-language speakers to understand. ${ }^{3}$ Nevertheless, despite the differences between individuals and cultural groups, there are models of humor that are common to many and focus on universal aspects of human experience. ${ }^{1}$
Correspondence: Sarah Abu-Kaf Conflict Management and Resolution Program, Ben-Gurion University of the Negev, PO Box 653, Beer-Sheva $841050 \mathrm{I}$, Israel

Tel +972 86428500

Fax +97286428550

Email aks@bgu.ac.il 
Humor therapy has been used in hospitals since the 1970s. Medical clowning uses laughter therapy and humor to alleviate the emotional and physical difficulties of patients and their families. ${ }^{1}$ The first professional clowns in hospitals began operating in New York in 1986, in a program called the Big Apple Circus Clown Care Unit. Today, there are professional medical clown programs in many countries, including Israel. The Dream Doctors program trains and employs clowns in hospitals in Israel. ${ }^{4}$ Medical clowns are often professional actors trained specifically for this job and equipped with a variety of skills and tools, such as music, poetry, magic, acting, and jokes. ${ }^{5}$

Research conducted in Israel and other countries has shown that medical clowning is highly effective in reducing physiological and emotional symptoms, including anxiety before surgery or other painful procedures. ${ }^{6-9}$ Medical clowning reduces the duration of crying and feelings of pain among children, as well as parental concern and anxiety. ${ }^{10-13}$ No studies have examined how medical clowning affects children from different cultures.

The Negev Bedouins are a unique and disadvantaged minority in Israel. Bedouin Arab society also differs from Jewish Israeli society in terms of language, religion, and other cultural characteristics. ${ }^{14}$ Bedouin society is highly collectivistic, patriarchal, and authoritarian, and differs greatly from Jewish Israeli culture in terms of its emphasis on collectivistic values. ${ }^{15}$ Over the last three decades, this society has undergone a rapid process of transition. ${ }^{16}$

We assumed that this population has its own unique models of humor based on the differences in the use of humor styles that were found among American Arabs. ${ }^{17}$ However, there is a possibility that the above-described processes of modernization and the medical clowns' use of universal elements of humor will lead to the observation of similar effects in the two groups. Therefore, this research aimed to assess the effectiveness of medical clowning in reducing levels of pain and anxiety among Bedouin and Jewish Israeli children and the influence of culture on that effectiveness.

\section{Methods}

\section{Type of study}

We employed a mixed-method research methodology (ie, methodology that involves collecting, analyzing, and integrating quantitative and qualitative data) within a pre-post study design. This study was conducted in four pediatric wards (A, B, C, and D), the Oncology Ward, the Orthopedics Ward, and the Oncology Outpatient Clinic of the Soroka University Medical Center in Beer-Sheva (excluding the Emergency and Intensive Care units). The children hospitalized in these wards experience different levels and types of pain including the pain of injections and having blood drawn, sensitivity to touch and feelings of unpleasant pressure, general discomfort, and postoperative pain. The medical center policy requires that medical-clowning services be made available to all hospitalized children (as long as their parents have no objection). The sample population was made up of children hospitalized in these wards who agreed to participate in the study and their parents.

The medical-clowning interventions were conducted by 10 medical clowns ( 7 females and 3 males). Each intervention lasted for 8-10 minutes, and included the use of word play, body language, and making faces, as well as props (eg, balloons) including objects found in the room (eg, a wheelchair) that were transformed into something amusing. All were Hebrew-speaking and one worked in both Russian and Hebrew. Among the Jewish population, the clowning intervention was carried out in Hebrew, with the exception of two occasions on which a clown spoke Russian with Russian-speaking children. Among the Bedouin population, the clowns mainly used pantomime or occasionally inserted isolated Arabic words (eg, "marhava" [hello], "ahalan v'sahalan" [welcome]) into their performance.

\section{Demographic data}

A questionnaire was used to obtain data on demographic variables, ${ }^{18,19}$ including age, gender, religion, country of birth, year of immigration, nation, level of religiosity, place of residence, parents' level of education, parents' occupation, and number of siblings.

\section{Pain, anxiety, and enjoyable components of the clowning intervention assessments} Faces pain scale-revised (FPS-R)

The level of pain felt by the child before and after the medicalclowning intervention was measured using the FPS-R ${ }^{17}$ tool (Figure 1). This tool was specifically designed for children aged $\geq 4-5$ years and has a high level of validity. ${ }^{17}$

\section{Subjective units of distress (SUDS) - anxiety level}

The levels of anxiety felt by the children and parents before and after the clowning intervention were measured using the

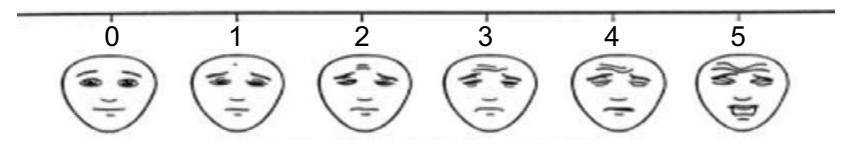

Figure I Faces pain scale-revised. 
SUDS tool. ${ }^{20,21}$ This scale is based on a range of 1-10 and participants were asked to note the number that reflects their feelings; " 1 " reflects a lack of any sense of anxiety and " 10 " reflects a high level of anxiety.

\section{Enjoyable components of the clowning intervention}

The enjoyable components of the clowning intervention were assessed based on a questionnaire developed for the present study, which consisted of eight statements relating to various components of the intervention. Participants were asked to indicate the extent to which they agreed with each statement on a 5-point scale ranging from 1 (not at all) to 5 (to a great extent).

\section{Qualitative study}

In order to assess the phenomenological experiences of the two groups with the clowning intervention, semi-structured interviews were conducted with the children and with their parents (who were present at the time of the intervention). The interviews with Jewish participants were conducted by a female, Jewish, Hebrew-speaking research assistant. The interviews with Bedouin participants were conducted by a male, Arab, Arabic-speaking research assistant. The semistructured interviews were based on questions referring to various elements of the clowning intervention. The collected data were analyzed.

\section{Statistical analysis}

After the preliminary analyses of sample characteristics, four main analyses were conducted. First, we conducted a pairedsample $t$-test to evaluate the reduction in the levels of pain and anxiety among the children and the level of anxiety among parents. Second, an unpaired $t$-test was performed to evaluate whether there was a difference in the effect of the intervention among the two groups. Then, we conducted a series of additional unpaired $t$-tests to evaluate the differences in the amount of enjoyment that the children from the two cultural groups derived from the various aspects of the clowning intervention. Finally, two hierarchical multiple regressions were conducted using the stepwise method, to estimate the unique contribution of the study variables to the prediction of the reduction of children's pain and anxiety.

\section{Ethical considerations}

The study was approved by the Helsinki Medical Ethics Committee of Soroka University Medical Center. Informed consent was provided by all participants, with the parents or guardians of the children consenting on behalf of the children.

\section{Results}

\section{The study population}

The quantitative section of the study included 89 children, 7.5-12 years old, and 69 parents, 19 of whom were Jewish and 50 of whom were Bedouin (Table 1). The majority of the Bedouin children lived in villages, whereas the majority of the Jewish children lived in the city. The parents in the Jewish group were more educated, more likely to be employed, and had smaller families, compared to the Bedouin parents.

The qualitative section of this study included 31 qualitative, semi-structured interviews with children from the quantitative sample (21 Jewish children and 10 Bedouin

Table I Demographic characteristics of the study population

\begin{tabular}{|c|c|c|c|c|}
\hline Characteristics & & Jewish $(n=39)$ & Bedouin $(n=50)$ & $p$-value \\
\hline Age, mean (SD) & & 9.8 (I.49) & $9.7(1.5)$ & 0.16 \\
\hline \multirow[t]{2}{*}{ Gender } & Male & 18 (46.2\%) & $25(50.0 \%)$ & 0.38 \\
\hline & Female & 21 (53.8\%) & $25(50.0 \%)$ & \\
\hline \multirow[t]{4}{*}{ Place of residence } & City & 29 (74.4\%) & $14(28.0 \%)$ & 0.000 \\
\hline & Village & - & $18(36.0 \%)$ & \\
\hline & Unrecognized Bedouin village & - & $18(36.0 \%)$ & \\
\hline & Other & $10(25.6 \%)$ & - & \\
\hline \multirow[t]{4}{*}{ Parental education level } & No formal education & $2(5.1 \%)$ & $13(26.0 \%)$ & 0.001 \\
\hline & Elementary school & $4(10.3 \%)$ & $6(12.0 \%)$ & \\
\hline & High school & 15 (38.5\%) & $26(52.0 \%)$ & \\
\hline & Higher education & 18 (46.2\%) & $5(10.0 \%)$ & \\
\hline \multirow[t]{3}{*}{ Parents' employment } & Both parents unemployed & $\mathrm{I}(2.6 \%)$ & $18(36.0 \%)$ & 0.000 \\
\hline & One working parent & $6(15.4 \%)$ & $24(48.0 \%)$ & \\
\hline & Both parents working & $32(82.1 \%)$ & $8(16.0 \%)$ & \\
\hline \multirow[t]{2}{*}{ Number of siblings } & $0-3$ & $30(77.0 \%)$ & $19(38.0 \%)$ & 0.004 \\
\hline & $4+$ & $9(23.0 \%)$ & $31(62.0 \%)$ & \\
\hline
\end{tabular}


children). We also conducted 18 semi-structured interviews with parents ( 8 Jewish parents and 10 Bedouin parents).

\section{Quantitative section}

The effectiveness of medical-clowning interventions in reducing levels of pain and anxiety was analyzed. Medical clowning significantly reduced pain $(p<0.01)$ and anxiety $(p<0.001)$. Parental anxiety was also significantly lower after the intervention ( $p<0.01$; Table 2$)$. The reduction in children's anxiety levels was higher among the Bedouin group than among the Jewish group ( $p<0.01$; Table 3$)$.

\section{Group differences in enjoyment of different components of the intervention}

Group differences were found in the level of enjoyment of two aspects of the clown intervention (ie, the clowns' facial expressions and the clowns' jokes about the medical staff or hospital; Table 4). The Bedouin children enjoyed the clown's facial expressions more than Jewish children did $(p<0.06)$. However, the Jewish children enjoyed the clown's jokes about the medical staff or hospital more than Bedouin children did $(p<0.05)$.

\section{Predicting the level of pain and anxiety post-intervention \\ Post-intervention pain levels}

The regression model explained $65 \%$ of the variance in the children's levels of pain following the intervention. As shown in Table 5, three of the variables in this model were found to be significant in predicting the children's level of pain postintervention: 1) the level of pain before the intervention; 2) the level of enjoyment of the verbal components of the clowning intervention; and 3 ) the level of enjoyment of the nonverbal components of the humor intervention.

\section{Post-intervention anxiety levels}

The regression model explained $73 \%$ of the variance in the children's levels of anxiety following the intervention. As shown in Table 6 , three of the variables in this model were found to be significant in predicting the children's level of anxiety post-intervention: 1) the level of anxiety pre-intervention; 2) the level of enjoyment of the nonverbal components of the clowning intervention; and 3) a two-way interaction term involving cultural group and enjoyment of the verbal components of the intervention. Further examination of this interaction term (as described in Figure 2) revealed that the ability to predict the level of anxiety after the clown's intervention based on the child's level of enjoyment of the verbal humor used in the intervention was significantly higher among the Bedouin group (34\%), compared to the Jewish group (8\%).

\section{The qualitative section}

Three main themes emerged from this part of the study.

Components that enhance the clowning intervention Children and parents from both cultural groups noted a variety of components that they found enjoyable.

\section{Verbal humor}

The verbal humor used by the clowns included a variety of jokes, for example, "the female clown gave me a rubber band and said stay in touch" and "the clowns asked if I could be their sister." Among the Jewish population, both adults and children, the content of the jokes was mentioned more. However, when referring to verbal humor, the responses of the Bedouin population did not give examples of the content of the jokes, but referred more to the various types of sounds, voices, and intonations used by the clowns. For example,

Table 2 Levels of pain and anxiety before and after the medical-clowning intervention within each cultural group

\begin{tabular}{|c|c|c|c|c|c|c|}
\hline Cultural group & Variable & & $M$ & SD & $t$ & $p$-value \\
\hline \multirow[t]{6}{*}{ Jews } & Children's level of pain & Before & 1.72 & 1.70 & 3.21 & 0.003 \\
\hline & & After & 1.21 & 1.63 & & \\
\hline & Children's level of anxiety & Before & 3.79 & 3.43 & 3.73 & 0.001 \\
\hline & & After & 2.74 & 2.84 & & \\
\hline & Parents' level of anxiety & Before & 4.42 & 2.76 & 2.93 & 0.009 \\
\hline & & After & 3.16 & 2.06 & & \\
\hline \multirow[t]{6}{*}{ Bedouin } & Children's level of pain & Before & 0.94 & 0.65 & 8.60 & 0.000 \\
\hline & & After & 0.18 & 0.39 & & \\
\hline & Children's level of anxiety & Before & 3.56 & 1.49 & 11.52 & 0.000 \\
\hline & & After & 1.68 & 0.98 & & \\
\hline & Parents' level of anxiety & Before & 3.88 & 2.25 & 8.2 & 0.000 \\
\hline & & After & 2.08 & 1.16 & & \\
\hline
\end{tabular}


Table 3 Reductions in levels of anxiety and pain among Jews and Bedouins

\begin{tabular}{llllll}
\hline Variable & & $\mathbf{M}$ & SD & $\boldsymbol{t}$ & $\mathbf{p}$-value \\
\hline Reduction in children's & Jews & $0.5 \mathrm{I}$ & $\mathrm{I} .00$ & $-\mathrm{I} .36$ & 0.180 \\
pain levels & Bedouins & 0.76 & 0.63 & & \\
Reduction in children's & Jews & $\mathrm{I} .05$ & $\mathrm{I} .76$ & -2.54 & 0.013 \\
anxiety levels & Bedouins & $\mathrm{I} .88$ & $\mathrm{I} .15$ & & \\
Reduction in parental & Jews & $\mathrm{I} .26$ & $\mathrm{I} .88$ & $-1.2 \mathrm{I}$ & 0.277 \\
anxiety levels & Bedouins & $\mathrm{I} .80$ & $\mathrm{I} .55$ & & \\
\hline
\end{tabular}

Table 4 Enjoyment of various components of the clown intervention within each cultural group

\begin{tabular}{llllll}
\hline Variable & & $\mathbf{M}$ & SD & $\boldsymbol{t}$ & $\mathbf{p}$-value \\
\hline Body language & Jews & 4.38 & 0.86 & -1.51 & 0.136 \\
& Bedouins & 4.62 & 0.64 & & \\
Facial expressions & Jews & 4.32 & 0.78 & -1.97 & 0.046 \\
& Bedouins & 4.62 & 0.64 & & \\
Verbal humor & Jews & 4.63 & 0.59 & 0.49 & 0.623 \\
& Bedouins & 4.56 & 0.73 & & \\
Costume & Jews & 4.03 & 1.27 & -1.88 & 0.065 \\
& Bedouins & 4.46 & 0.79 & & \\
Accessories & Jews & 4.59 & 0.96 & 0.63 & 0.529 \\
& Bedouins & 4.48 & 0.74 & & \\
Joking with doctors & Jews & 4.20 & 0.92 & -0.62 & 0.541 \\
& Bedouins & 4.38 & 0.83 & & \\
Jokes regarding medical & Jews & 4.57 & 0.76 & 0.75 & 0.456 \\
devices & Bedouins & 4.40 & 0.76 & & \\
Jokes regarding the medical & Jews & 4.83 & 0.41 & 2.33 & 0.041 \\
staff and hospital & Bedouins & 4.36 & 0.83 & & \\
\hline
\end{tabular}

Table 5 Hierarchical multiple regression model for predicting the change in the children's level of pain following the intervention based on children's levels of pain before the intervention and their enjoyment of the clowns' verbal and nonverbal humor

\begin{tabular}{lllll}
\hline Variable & $\boldsymbol{\beta}$ & $\boldsymbol{P}$ & $\boldsymbol{R}^{\mathbf{2}}$ & $\boldsymbol{F}$ \\
\hline Step I & & & & \\
Children's pain pre-intervention & 0.69 & 0.000 & 0.47 & 59.64 \\
Step 2 & & & & \\
Children's pain pre-intervention & $0.5 \mathrm{I}$ & 0.000 & 0.16 & 29.39 \\
Children's enjoyment of verbal humor & -0.44 & 0.003 & & \\
Step 3 & & & & \\
Children's pain pre-intervention & 0.48 & 0.001 & 0.02 & 4.18 \\
Enjoyment of verbal humor & -0.35 & 0.009 & & \\
Enjoyment of nonverbal humor & -0.19 & 0.042 & & \\
\hline
\end{tabular}

Notes: In the interest of clarity, only variables that contributed significantly to the model are presented in the table. $\beta$, standardized regression coefficient (refers to how many standard deviations a dependent variable will change, per standard deviation increase in the predictor variable), $R^{2}$, proportion of variance explained in each step.

when asked what they saw as the funniest thing the clown did, they mentioned the "clown's voice" and "childish speech". In addition, the verbal-auditory component had a strong soothing effect among the Jewish participants. However, in contrast, children from the Bedouin population noted
Table 6 Hierarchical multiple regression model for predicting the change in children's anxiety levels following the medicalclowning intervention based on children's levels of anxiety before the intervention, their enjoyment of nonverbal humor, and enjoyment of verbal humor $\times$ culture interaction

\begin{tabular}{lllll}
\hline Variable & $\boldsymbol{\beta}$ & $\boldsymbol{p}$ & $\boldsymbol{R}^{\mathbf{2}}$ & $\boldsymbol{F}$ \\
\hline & & & & $\begin{array}{l}\text { Step I } \\
\text { Children's anxiety pre-intervention }\end{array}$ \\
& 0.74 & 0.000 & 0.55 & 81.82 \\
& & & & Step 2 \\
Children's anxiety pre-intervention & 0.60 & 0.000 & 0.15 & 32.74 \\
Children's enjoyment of nonverbal humor & -0.41 & 0.005 & &
\end{tabular}

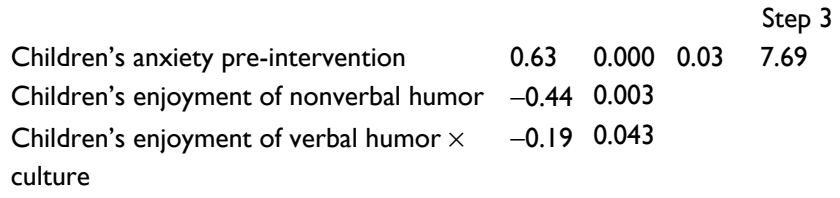

Notes: In order to keep the data organized, only variables with significant contribution to the model are presented in the table. $\beta$, standardized regression coefficient; $R^{2}$, proportion of variance explained in each step.

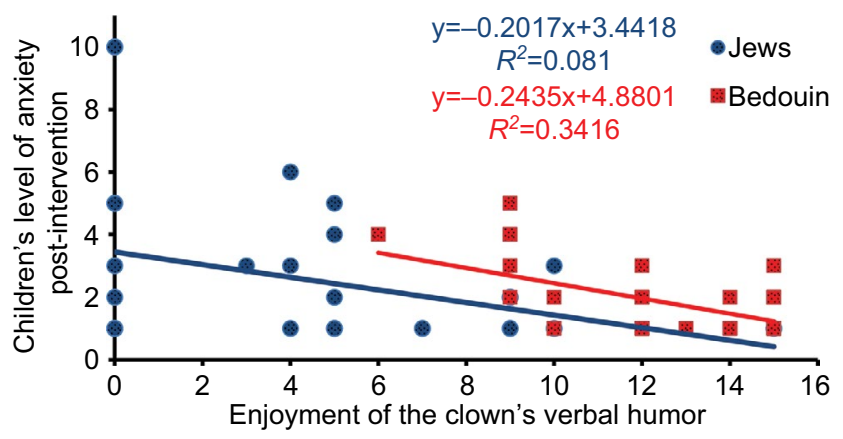

Figure 2 The ability to predict children's anxiety levels after the intervention based on the interaction between the child's enjoyment of the clown's verbal humor and the child's culture.

nonverbal humor as having a soothing effect, for example, "playing soccer with a balloon," and "(if the clown had) brought cotton and games."

\section{Nonverbal humor}

Some interviewees referred to various props used by the clowns, such as dolls, balloons, bubbles, gloves, whistles, card tricks, and dolls. It should be noted that among the Bedouin population, the balloons were considered the funniest prop. Some interviewees referred to the clown's body language, including dancing and how the clown walked.

When the participants were asked about the funniest thing they enjoyed about the clown, the Jewish participants did not make any mention of what the clown was wearing, but there was a request both from the children and from the parents that the clown's clothing be more colorful and funny. In contrast, among the Bedouin population, a number of children referred to the clown's red nose as being the funniest thing. 


\section{Less enjoyable components of the clowning intervention}

The majority of children and parents found all of the components of the intervention to be enjoyable. Some noted a game, magic trick, or a specific dance that they enjoyed less. A certain proportion of the respondents referred to humor regarding values or social taboos. Among the Jewish children and parents, references were made to humor regarding sirens and missile attacks that occurred during Operation Protective Edge (eg, throwing a toy missile), humor regarding serious illness and the difficulty involved with it, and vandalizing public property as the humor they found the least funny. Among the Bedouin population, both the children and parents referred to jokes made with the medical staff as the least funny.

\section{Overall feedback regarding the helpfulness of the clowning intervention}

All of the children and parents from both groups felt the clown helped them. Some of the Jewish participants specified the kind of help they had received; the children referred mainly to reduced pain, reduced stress, and increased laughter: "helped me not think about the pain and reduced the stress," "laugh and smile helped," and "areas that hurt were less painful."

\section{Discussion}

Our main finding was that the medical-clowning intervention was more helpful in reducing anxiety among the Bedouin children. This finding may be linked to a different stimulation threshold toward the clown among the children of the two cultural groups, due to the Bedouin children's lack of previous exposure to clowns. It has been suggested that a substantial amount of our perceptual experience is related to stimuli recently experienced. ${ }^{22}$ Therefore, minimal exposure to a particular stimulus will increase one's sensitivity to that stimulus. ${ }^{23}$ This observation is reinforced by the work of Elroy ${ }^{5}$ who, in a qualitative study of medical clowning at Hadassah Ein Kerem Hospital in Jerusalem, found that the clown figure is not familiar in Arab society and that Arab children react with more surprise to clowns, compared to Jewish Israeli children. ${ }^{5}$ This means that their stimulation threshold for the clown figure is lower, which makes them more sensitive to the clown figure. This explains why the medical-clowning intervention was more effective among that population.

We found that the medical-clowning intervention reduced levels of pain and anxiety among children and also reduced the level of anxiety among parents from Bedouin and Jewish populations. This finding is consistent with other studies that have been carried out locally and in other countries. ${ }^{7,911-13,24}$ The efficacy of the medical-clowning intervention may be explained by the ability to distract patients, especially children. ${ }^{25}$ An earlier study demonstrated an association between medical-clowning interventions and increased activity in the subcortical regions of the brain, including the amygdala, the ventral striatum, and the midbrain, which are involved in experiencing positive rewards. ${ }^{26}$

This study also revealed group differences in the levels of enjoyment derived from different components of the clowning intervention. Generally, the Bedouin children derived less enjoyment from the clowns making fun of the medical staff. This finding may be explained by social values regarding respect for authority figures in the Bedouin society. $15,27,28$

We also examined how the nonverbal component of the intervention, such as the various props used by the clowns (eg, dolls, balloons, and bubbles) and the clown's body language and behavior, predicted levels of pain and anxiety. The higher the level of enjoyment of this component, the lower the levels of pain and anxiety experienced by the child. More support for this finding was found in the qualitative part of the study, in which the children of both populations and the Bedouin parents preferred the nonverbal humor. Furthermore, children from the Bedouin population noted that nonverbal humor had a soothing effect. The preference and the importance of the nonverbal component may be related to the cognitive development stage of the Bedouin and Jewish children (concrete operational) and the lower level of Hebrew knowledge and fluency among Bedouin children and their parents. ${ }^{29,30}$

Another interesting finding is that the level of enjoyment of the verbal humor was a better predictor of the reduction in anxiety levels, particularly among the Bedouin group. This finding is totally unexpected because none of the 10 clowns in the hospital spoke Arabic. Therefore, we can assume that some of the Bedouin children could not understand the verbal component of the intervention. A possible explanation for this unexpected finding was found in the interviews, in which some of the Bedouin children and parents who were asked about the verbal components of the intervention referred to the various sounds and intonations used in the clown's performance rather than the verbal content of the performance. In the interviews, Bedouin children and their parents also noted the need to include Arabic-speaking medical clowns among the services offered by the hospital.

We also found that Bedouin participants were less amused by the humor regarding the hospital and medical staff, whereas Jewish participants were less amused by the 
humor regarding missiles and sirens that sounded during the Operation Protective Edge, humor regarding illness (eg, use of a wheelchair), and humor that involved damaging public property (eg, scribbling on the hospital's garbage bins). This finding demonstrates the different cultural borders of humor. In other words, in the different cultural groups, there are taboos and issues about which it is less legitimate to joke.

\section{Limitations and directions for future research}

There are a number of limitations to this study. The first limitation is the absence of a control group. It was unethical to prevent or delay the clowning intervention for hospitalized children, in order to eliminate cofounding variables. In future research, positive control groups (including other interventions) should be included. The second limitation is related to the fact that the clowns spoke Hebrew, but not Arabic (the first language of the Bedouin children and their parents). Future studies should include medical centers that have clowns who speak Arabic and the generalizability of the current findings should be tested in those settings.

\section{Conclusion}

Medical-clowning intervention is effective in reducing pain and anxiety among Jewish and Bedouin children, and anxiety among parents from these two cultural groups. However, Bedouin children can better enjoy the contribution of this intervention in reducing anxiety levels that may be stronger as they are a minority within the hospital. The findings highlight the importance of using this type of intervention when working with this population. Our findings regarding issues of language sensitivity and carefulness with regard to social taboos of different cultures, the importance of using tone and nonverbal noises, and the development of universal, nonverbal humor have important implications for intercultural clown training.

The main methodological implication of this work is that it underscores the importance of mixed methods for understanding results when working with different cultures within a health system.

\section{Acknowledgments}

This study was financially supported by a grant from the Magi and Adelis Foundations, Israel. This paper was presented at the 36th Annual Conference of the Stress and Anxiety Research Society (STAR)as a poster presentation with interim findings.

\section{Disclosure}

The authors report no conflicts of interest in this work.

\section{References}

1. Sober A. Humour: Man's Nature is to Laugh. Jerusalem: Karmel; 2009. Hebrew.

2. Zeidman I. Humor. Tel Aviv: Papyrus; 1994. Hebrew.

3. Bell ND. How native and non-native English speakers adapt to humor in intercultural interaction. Humor. 2007;20(1):27-48.

4. Dream Doctors [homepage on the Internet]. The Dream Doctors Project: medical clowning in action; 2016. Available from: http://www. dreamdoctors.org.il/en. Accessed January 20, 2016.

5. Elroy A. Qualitative Research Concerning Medical Clowns at Hadassah Ein Karem Hospital [dissertation]. Jerusalem: Hebrew University; 2006. Hebrew.

6. Alan E, Prudhoe G, Weaver K. Does clowning benefit children in hospital? Views of Theodora Children's Trust clown doctors. J Child Young People Nurs. 2007;1(1):24-28.

7. Golan G, Tighe P, Dobija N, Perel A, Keidan I. Clowns for the prevention of preoperative anxiety in children: a randomized controlled trial. Paediatr Anaesth. 2009;19(3):262-266.

8. Goldberg A, Stauber T, Peleg O, Hanuka P, Eshayek L, Confino-Cohen R. Medical clowns ease anxiety and pain perceived by children undergoing allergy prick skin tests. Allergy. 2014;69:1372-1379.

9. Hansen LK, Kibaek M, Martinussen T, Kragh L, Hejl M. Effect of a clown's presence at botulinum toxin injections in children: a randomized, prospective study. J Pain Res. 2011;4:297-300.

10. Armfield NA, Bradford N, Spitzer P, Smith AC. Humor sans frontiers: the feasibility of providing clown care at a distance. Telemed $J E$ Health. 2011;17(4):316-318.

11. Felluga M, Rabach I, Minute M, et al. A quasi randomized-controlled trial to evaluate the effectiveness of clown therapy on children's anxiety and pain levels in emergency department. Eur JPediatr. 2016;175(5):645-650.

12. Meiri N, Ankri A, Hamad-Saied M, Konopnicki M, Pillar G. The effect of medical clowning on reducing pain, crying, and anxiety in children aged 2-10 years old undergoing venous blood drawing - a randomized controlled study. Eur J Pediatr. 2016;175:373-379.

13. Vagnoli L, Caprilli S, Messeri A. Parental presence, clown or sedative medication to treat preoperative anxiety in children: what could be the most promising option? Paediatr Anaesth. 2010;20:937-943.

14. Al-Haj M. Kinship and modernization in developing societies: the emergence of instrumentalized kinship. J Comp Fam Stud. 1995;26:311-328.

15. Hofstede G, Hofstede GJ. Cultures and Organizations: Software of the Mind. 2nd ed. New York, NY: McGraw-Hill; 2005:16.

16. RHA Center for Bedouin Studies and Development. Statistical Yearbook of the Bedouins in the Negev. Beer-Sheva, Israel: Ben-Gurion University; 2010.

17. Kalliny M, Cruthirds KW, Minor MS. Differences between American, Egyptian and Lebanese humor styles: implications for international management. Int J Cross Cult Manag. 2006;6(1):121-134.

18. Abu-Kaf S, Braun-Lewensohn O. Paths to depression among two different cultural contexts: comparing Bedouin Arab and Jewish students. J Cross Cult Psychol. 2015;46(4):612-630.

19. Abu-Kaf S, Priel B. Dependent and self-critical vulnerabilities to depression in two different cultural contexts. Pers Individ Dif. 2008;44:689-700.

20. Hicks CL, Baeyer CL, Spafford PA, Korlaar I, Goodenough B. The Faces Pain Scale - revised: toward a common metric in pediatric pain measurement. Pain. 2001;93:173-183.

21. Wolpe J. The Practice of Behavior Therapy. New York: Pergamon; 1969.

22. Kim D, Bae H, Park YC. Validity of the subjective units of disturbance scale in EMDR. J EMDR Pract Res. 2008;2(1):57-62.

23. Webster MA. Evolving concepts of sensory adaptation. F1000 Biol Rep. 2012;4:21.

24. Sridharan K, Sivaramakrishnan G. Therapeutic clowns in pediatrics: a systematic review and meta-analysis of randomized controlled trials. Eur J Pediatr. 2016;175(10):1353-1360. 
25. Alcantara PL, Wogel AZ, Rossi MIW, Neves IR, Sabates AL, Puggina AC. Interaction effect of clowns in vital signs and non-verbal communication of hospitalized children. Rev Paul Pediatr. 2016;34(4):432-438.

26. Bekinschtein TA, Davis MH, Rodd JM, Owen AM. Why clowns taste funny: the relationship between humor and semantic ambiguity. $J$ Neurosci. 2011;31:9665-9671.
27. Al-Krenawi A. Ethno-Psychiatry in the Arab Bedouin Community in the Negev. Tel Aviv: Ha-Kibbutz Ha-Meuchad; 2000. Hebrew.

28. Berger KS. The Developing Person Through the Life Span. 7th ed. New York, NY: Worth; 2008:43.

30. Piaget J. The role of action in the development of thinking. Knowledge and Development. New York, NY: Springer; 1977:17-42.

\section{Publish your work in this journal}

The Journal of Pain Research is an international, peer reviewed, open access, online journal that welcomes laboratory and clinical findings in the fields of pain research and the prevention and management of pain. Original research, reviews, symposium reports, hypothesis formation and commentaries are all considered for publication.
Dovepress

The manuscript management system is completely online and includes a very quick and fair peer-review system, which is all easy to use. Visit http://www.dovepress.com/testimonials.php to read real quotes from published authors. 